14 had smoked cigarettes. Five patients had had a postmortem examination but only one showed evidence of asthma.

\section{Conclusions}

The actual death rate from asthma in West Cumbria seems to be much lower than mortality statistics suggest. Many older patients who probably neither had asthma nor died of asthma may be being entered into the statistics for asthma mortality because of inappropriate use of the word asthma on death certificates, diagnostic transfer, or coding changes.

Concern has been expressed over the accuracy of death certificates in general, ${ }^{5}$ and certification of death from asthma in particular, ${ }^{7}$ but my study suggests that the inaccuracy may be much greater than previously realised. If the experience in other districts is similar to that in West Cumbria, a mortality from asthma of 2000 asthma deaths a year nationally is probably much too high. Perhaps all deaths recorded as due to asthma should be analysed by an independent panel of experts to ensure that the national statistics are correct.

I thank Dr C MacLeod, senior registrar in community health, West Cumbria Health Authority, for help with statistics and information.

1 British Thoracic society. Deaths from asthma in two regions of England. BMJ 1982;285:1251-5.

2 Burney P. Asthma mortality in England Wales; evidence for a further increase, 1974-1984. Lancet 1986;ii:323-6.

3 Rea HH, Scraff R, Jackson R, Beaglehole R, Fenwick J, Sutherland DC. A case controlled study of deaths from asthma. Thorax 1986;41:83-9.

4 Eason J, Markowe HLJ. Controlled investigation of deaths from asthma in hospital in the North East Thames region. BMF 1987;294:1255-8.

5 Burney PGJ. Asthma deaths in England and Wales 1931-85. Evidence for a true increase in asthma mortality. $\mathcal{F}$ Epidemiol Community Health 1988;42:316. 6 Cochrane AL, Moore F. Death certification from the epidemiological point of view. Lancet 1981;ii:742-3.

7 British Thoracic Association. Accuracy of death certification in bronchial asthma. Thorax 1984;39:505.

(Accepted 12 November 1992)

\title{
Education and training of preregistration house officers: the consultants' viewpoint
}

\author{
David H Wilson
}

\section{Abstract}

Objective-To determine the opinions, attitudes, and requirements of consultants responsible for preregistration house officers in the light of the General Medical Council's Recommendations on General Clinical Training.

Design-A questionnaire was piloted asking 28 questions under the headings professional details, present training arrangements, effectiveness of current training, and perceived help required for implementing the recommendations.

Setting-Two teaching hospitals and nine district general hospitals in the Yorkshire region.

Subjects-33 consultants (19 physicians, 14 surgeons) responded to an hour long interview.

Results-The traditional teaching ward round, with clinical meetings, was the main educational provision for house officers. Under a quarter of respondents provided specific teaching, which rarely exceeded 30 minutes weekly. Many delegated teaching to other junior or non-medical staff. Few consultants assessed the effectiveness of teaching, and feedback to juniors was rudimentary. There was strong support for the apprenticeship system and concern that it should not be downgraded. Appointing educational supervisors and introducing a structured educational programme were approved theoretically. Pressure on consultants to work faster, participate in audit and management, and accept financial responsibility for their clinical work, coupled with the reduction in junior doctors' hours, were considered to militate against educational developments. Many respondents felt frustrated and powerless. They would welcome an increased educational role but considered there must be conceptual, contractual, and financial changes.

Conclusions-Fundamental changes are required by both consultants and management before the preregistration year can have proper educational value. Training in educational methods for consultants and a structured curriculum and formative assessment for trainees require recognition and financial support.

\section{Introduction}

In January 1992 the General Medical Council issued revised recommendations on general clinical training. These state, "The goodwill of consultants and of principals in general practice to be appointed as educational supervisors is essential if house officers' expectations are to be fulfilled. This will be forthcoming only if there is full discussion between the universities and all concerned with the pre-registration year, and a realisation by all of the importance of the year to the young doctor." This paper results from initiating that discussion in the Yorkshire health region.

The concept of a nominated personal educational supervisor for each preregistration house officer is an innovation in the recommendations. Currently in a six month appointment a house officer may be attached to one team of consultants for three months and then change to a second team. There is therefore a danger that no one consultant will take specific responsibility for the house officer throughout the whole six months. The recommendations state, "The educational supervisor should help with both professional and personal development and be aware of the PRHO's individual needs ... provide feedback on their clinical progress ... and should personally undertake, and not delegate their tutorial functions."'

\section{Present survey}

The new recommendations were circulated to all consultants concerned in training preregistration house officers in the region. Through conversation, it was soon realised that although consultants welcomed the concept of the educational supervisor theoretically, they did not all wish to be burdened with this increased responsibility. Consequently, to test this viewpoint three educationalists and two consultants helped prepare a questionnaire asking 28 questions under four headings: professional details of the consultants; their present arrangements for training preregistration house officers; their assessment of the effectiveness of this training; and their view of the help required for 


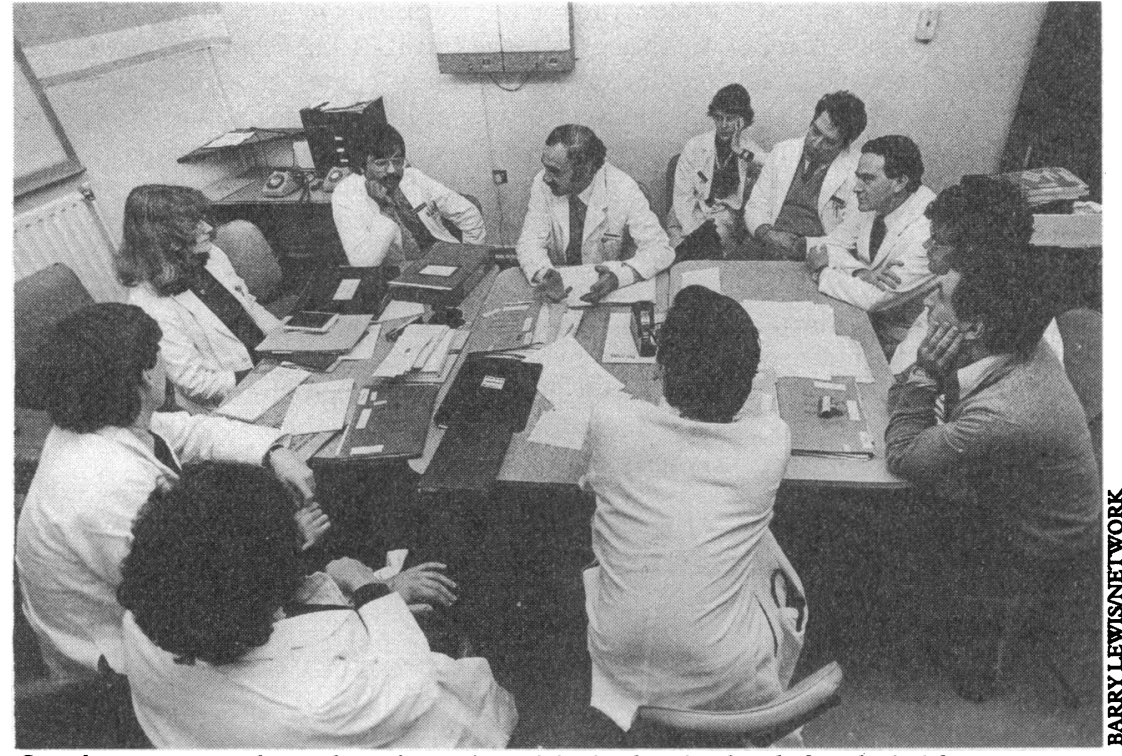

Consultants are expected to teach, yet ferv receive training in educational methods and principles

implementing the new recommendations. The questionnaire was piloted, then revised, and a final version agreed. Forty consultants (20 physicians, 20 surgeons) were asked to participate in an hour long interview at a mutually convenient time during June 1992. Two replied that they would not be available in June and alternatives were contacted. Four other consultants did not reply even after a second letter and phone calls to their secretaries. Of the 36 who agreed to participate, three eventually could not find the time. Data from 33 interviews (19 physicians, 14 surgeons) were therefore available for analysis.

\section{Results}

PROFESSIONAL DETAILS

Of the 33 respondents, four were aged under 40,18 were between 40 and 50 , and 11 were over 50 . Nine worked in the Leeds teaching hospitals (General Infirmary and St James's University Hospital) and the other 24 in hospitals in Bradford, Halifax, Harrogate, Huddersfield, Hull, Otley, Seacroft, Wakefield, and York. On average the consultants were responsible for 22 inpatient beds (range 12 to 40). Sixteen of them had a house officer for a full six months. Sixteen changed house officers after three months and one changed every two months. During the preceding two years the consultants had trained a total of 227 preregistration house officers.

Subsequent analysis of the responses to the questionnaire showed no significant difference between teaching hospital and non-teaching hospital consultants, nor was there any discernible difference in responses with the respondent's age.

\section{PRESENT TRAINING ARRANGEMENTS}

Fifteen consultants sent introductory information in advance to new house officers, giving details of their duties and training programme. All hospitals held induction courses but few of the consultants were personally involved. Teaching ward rounds were the standard method of instruction and 27 consultants said their house officers also attended regular clinical meetings. However, teaching was for all levels of junior doctors together. Only eight consultants held one to one teaching or tutorials for their house officers and most consultants estimated their total teaching time to be less than 30 minutes a week. Twenty four respondents stated that they delegated some of the responsibility for house officer teaching to other junior medical staff and to ward sisters. All but one of the consultants said they provided feedback on the house officer's progress, although one admitted it was little more than "five minutes at the end to say thank you."

The apprenticeship experience was seen by almost all of the consultants as the most powerful contribution to house officer training. Being caught up within the clinical culture, learning by immersion, and absorbing the practice and principles of the firm may seem to leave the educational process to chance but all respondents pleaded that any changes in the preregistration year should not depreciate or downgrade the contribution of apprenticeship to the training process.

EFFECTIVENESS OF CURRENT TRAINING

In response to the question "How do you currently assess the effectiveness of your teaching?" 23 consultants said they did not. Only five actively sought feedback from their house officers. Others relied on informal feedback such as, "many of our house officers want to return here to work as senior house officers." When asked "Would you like more feedback about the effectiveness of your teaching?" 25 replied that they would.

"What do you find difficult about your teaching role?" produced an almost unanimous response: lack of time on the part of either the consultant or the house officer, or both. Pressures of work and increasingly other competing commitments were squeezing out time for teaching.

When asked, "Should all consultants retain their teaching role or should some specialise and be specifically trained as educationalists?" 27 said all should be trainers; five of the 27 , however, thought that there should also be specialised consultant trainers. Only six respondents were in favour of training being restricted to those who had been trained to provide it.

HELP REQUIRED TO IMPLEMENT NEW RECOMMENDATIONS

Time, training, and funding were the dominant themes in most responses. The recommendations state, "Time should be provided for education, by means of hospital based programmes relevant to this stage of the doctors' training and also time allowed for private study." A typical response was that pressure is being applied to consultants to increase their workload, be involved in management, accept financial responsibility, and give time for audit. Concurrently juniors' working hours are being reduced. If both consultants and house officers are to give dedicated time to education, then less clinical work will be achieved and waiting lists will grow longer. The implications of such a change must be recognised by management and by the public.

Eighteen of the 33 respondents said they would welcome training in educational methods and principles. Nineteen said they would appreciate occasional seminars at which they could meet other house officer trainers. One senior consultant stated that taking this hour to reflect on his role as a teacher and trainer was a unique experience in his career.

"The goodwill of consultants appointed as educational supervisors is essential. ..." Although it is accepted their goodwill is necessary, respondents expect that there will be financial implications of implementing the recommendations. These may be modest but they must be recognised.

\section{Discussion and conclusions}

After this series of hour long consultant interviews the interviewers were left with three dominant impressions. Firstly, there was wide agreement that house officer training is unsatisfactory. Consultants generally did not see the preregistration year as an educational 
process. Hence to give the title "educational supervisor" to a consultant will have little effect unless there is a profound change in the way in which consultants and hospital managers view the role of the house officer. Dedicated time for training, education, and study will be difficult to find in an environment where consultants feel they are being subjected to increasing pressure and juniors' hours are being reduced but the clinical workload is increasing.

Secondly, consultants receive no training in educational methods. Most would welcome it and would also appreciate an opportunity to meet with other trainers. This will require funding.

Thirdly, there is a feeling of frustration and powerlessness among consultants. At a time of increasing demands for clinical work, audit, management, and financial responsibility the GMC seems to be imposing a further requirement for the preparation, provision, and assessment of structured education and involvement in the professional and personal development of house officers.

The GMC's appeal for the goodwill of consultants to underwrite the improvements in house officer training, which are envisaged in its 1992 recommendations on general clinical training, comes at a time when this commodity is losing ground under pressure from other competing demands.

The appointment of clinical supervisors and the introduction of structured education and training will be effective only if there are profound conceptual changes in the understanding of the purpose of the preregistration year, if there are contractual agreements to enable the educational supervisor to fulfil the role, and if there is financial provision for the training of trainers and regular formative assessment of the trainees.

I thank the five members of Yorkshire Health Associates who conducted the interviews and all the consultants who took time to respond to questions and reflect on their role as trainers.

1 General Medical Council. Recommendations on general clinical training. London: GMC, 1992.

(Accepted 16 December 1992)

\section{Medical Education}

\section{The preregistration year}

\section{Stella Lowry}

This is the seventh in a series of articles examining the problems in medical education and their possible solutions
British Medical Journal, London WC1H 9JR

Stella Lowry, assistant editor

BMF 1993;306:196-8
In Britain basic medical education ends with a year as a preregistration house officer in approved hospital posts that provide the general clinical experience required before full registration with the General Medical Council. In theory the preregistration year is an integral part of basic medical education, which is reflected in the fact that the universities have statutory responsibility for this year. But this is also the first time that a young doctor takes on daily clinical responsibility for patients' care, and in reality the service element provided by preregistration house officers underpins the medical care provided in many of our hospitals.

The long hours worked by preregistration house officers, the high service commitment, and the low rating given to the educational aspects of the job have led to numerous criticisms of this part of medical education. Many reports have drawn attention to high levels of dissatisfaction among junior doctors. One survey, conducted in 1986, found that nearly half of the doctors who had graduated in 1981 regretted their choice of career.' A recent report by the BMA has confirmed that stress and disillusionment are common among young doctors, ${ }^{2}$ and various reports have pinpointed the preregistration year as a time of considerable unhappiness, up to half of preregistration house officers suffering from clinical depression during the year. ${ }^{34}$

A common criticism levelled at the preregistration year concerns the long hours of work. Despite recent government initiatives most preregistration house officers still work over 72 hours a week. What causes most distress, however, is not the total number of hours but the inappropriate work expected of junior doctors during this time. ${ }^{5}$ Recent studies have confirmed that large parts of a house officer's week are spent on routine tasks like taking blood, filling in forms, arranging beds for routine and emergency admissions, and filing laboratory reports. ${ }^{6}$ The GMC has acknowledged these criticisms in its most recent set of guidelines on what the preregistration year should provide. ${ }^{7}$ Universities are supposed to ensure that all posts approved by them for general clinical experience meet the GMC's recommendations. In this article I shall look at what has been proposed by the GMC, whether this can or should be implemented, what the interested parties think about the recommendations, and whether there are any other ways of ensuring that newly qualified doctors are not put off their careers completely before they have properly begun.

\section{What the GMC recommends}

In the introduction to its latest guidelines the GMC states that the preregistration year should be "an enjoyable and profitable experience" and calls on the universities to "exercise greater control than hitherto over the duties undertaken . . . , the supervision of house officers, the general education provided and the monitoring of house officers' progress." The document sets out various skills that should be mastered during the year and also states that time should be set aside for education, including protected time within the working week for private study. House officers should have named educational supervisors, usually their consultants, who ensure that the educational objectives of the year are met and help with any personal problems that may arise. The educational supervisor is supposed to ensure that the house officer is not "overwhelmed by clinical commitments, overburdened by responsibilities inappropriate to the experience acquired, or undertaking an excessive on-call commitment." The supervisor is meant to undertake, and not delegate, various tutorial functions, including the induction of the new house officer, regular monitoring of progress and assessment of competence, encouraging participation in educational activities, and giving careers advice.

\section{Can it be done?}

These may all be worthy aims, but they are so far removed from the reality of most house officers' experiences as to be laughable. How is a consultant physician or surgeon in a busy hospital supposed to 